\title{
Treatment of Cell-Mediated Immunodeficiency with Calf Thymic Hormone (T.P.I.)
}

\author{
E.G. DAVIES AND R.J. LEVINSKY ${ }^{(22)}$ \\ Hospital for Sick Children, Great Ormond Street, London and Institute of Child Health, Guilford Street, London, \\ England
}

\begin{abstract}
Summary
Eight children, four with combined immunodeficiencies and four with isolated $T$ cell defects were treated with TPI, a crude calf thymic extract. Assessment of response was made on clinical grounds and by monitoring of immune function ( $T$ and $B$ cell numbers, immunoglobulin levels, PHA response and delayed cutaneous reaction to Candida antigen). One child with severe combined immunodeficiency showed marked clinical improvement together with reconstitution of $T$ cell numbers and, surprisingly, $B$ cell numbers and immunoglobulin production. Two further children, one with a form of combined immunodeficiency and the other with a $T$ cell defect and extensive cutaneous herpes simplex infection, showed benefit from therapy though in the latter we could not demonstrate that this was important in clearing the virus infection. None of the other children showed any consistent improvement either clinically or on testing. We found no evidence of toxicity, allergy or other adverse effects of therapy.
\end{abstract}

\section{Speculation}

Children with deficiencies of cell mediated immunity including some of those with combined immunodeficiencies can benefit from thymic hormone therapy. It may be that therapeutic trial is the only way of determining which children will respond.

The differentiation and maturation of fully immunocompetent $T$ cells is under the control of a variety of thymic factors. Cell contact with both thymic epithelial cells and reticular dendritic cells affect maturation but in addition humoral factors produced by the thymus gland are also necessary (8). Several preparations of these thymic humoral factors have been described; the crude calf thymus extract fraction $V$ (thymosin) (9) is now thought to contain several biologically active peptides (17). Thymopoetin, a 49 amino acid polypeptide, extracted from human tissues has been sequenced (16) and the active part of the molecule, a 5 amino acid polypeptide (TP5) synthesized (10). Similar biologic activity is found in a nona peptide isolated from human serum, Factor thymique serique (2) though there is no sequence homology between these two peptides. It seems likely that a family of thymic hormones exist, affecting different stages of $T$ cell maturation.

Thymostimulin (TPI manufactured by Serono Laboratories), an extract of calf thymus similar to thymosin fraction $\mathrm{V}$ has been shown to induce $\mathrm{T}$ cell markers on lymphocytes from $\mathrm{T}$ deficient individuals (7), and when administered to these individuals, to produce clinical improvement together with increased $T$ cell numbers and function (1).

We report our experience using TPI in eight children, all of whom had defective cellular immunity either as an isolated $\mathrm{T}$ cell deficiency or as part of a combined immunodeficiency. In all cases, no other specific immunologic treatments were feasible.

\section{MATERIALS AND METHODS}

Patients. Eight children aged between 2 months and 10 years were studied during treatment. Informed consent was obtained from all the parents before initiating therapy. The study was approved by the ethical committee of the hospital.

Thymic hormone. Calf thymic extract (TPI) was supplied by Serono Laboratories. The method of extraction and purification has been described in detail elsewhere (4). Briefly, ammonium acetate extraction of minced calf thymuses is followed by two precipitation steps with ammonium sulphate. The precipitate from the second step is subjected to ultrafiltration and then purified on Sepharose G25 and G50. The resulting extract contains a family of polypeptides with molecular weights lower than 12,000 . There are two main bands on polyacrylamide gel electrophoresis. Standardisation of the activity of the extract is performed by comparing it to a standard preparation of TPI in a bioassay using induction of rosette forming cells in guinea pig spleen preparations (5).

The same preparation was used clinically and for the in vitro tests. The dose used for treatment (unless otherwise stated in case reports) was $1 \mathrm{mg}$ (of protein) per kilogram body weight, given daily by intramuscular injection for 5 days and then twice weekly for periods ranging between 2-15 months.

$T$ cells. $T$ cells were estimated by a standard rosetting assay (18) using neuraminidase-treated sheep red blood cells. For in vitro effect of TPI the cells were first incubated at $37^{\circ} \mathrm{C}$ for $30 \mathrm{~min}$ with either 5 or $50 \mu \mathrm{g} / \mathrm{ml}$ of the extract and any increase in the $\%$ of $\mathrm{E}$ rosette forming cells noted. Normal values for $\mathrm{E}$ rosette positive cells fall between $55-75 \%$ of mononuclear cells and no increase occurs in normal individuals after incubation of their lymphocytes with TPI.

$B$ cells. B cells were counted by immunofluorescence using fluorescinated polyvalent anti-human immunoglobulin (11). (Normal values $8-18 \%$ of total lymphocytes).

Phytohaemagglutinin (PHA) response. PHA response was measured using a whole blood technique as previously described (11). PHA (Wellcome) was added to $200 \mu$ liter volumes of whole defibrinated blood (diluted 1 in 20 ) in a range of concentrations from $1-8 \mu \mathrm{g} / \mathrm{ml}$. After $72 \mathrm{~h}$ incubation, tritiated thymidine uptake was measured and the result expressed as a stimulation index (ratio of PHA induced to control uptake). (Normal value $>10$ ). TPI (if added) was at a final concentration of $10 \mu \mathrm{g} / \mathrm{ml}$. (This produces no increase in normal subjects).

Delayed hypersensitivity. This was assessed by intradermal injection of $0.1 \mathrm{ml}$ of Candida extract (Bencard 1\% D.H.S.) and read at $48 \mathrm{~h}$. A positive result was recorded if there was any induration (which was measured in $\mathrm{mm}$ ) at the site of injection.

\section{RESULTS}

Regular monitoring of blood counts, biochemical tests for renal and liver function and urinary sediment examination was performed. Most of the children had minimally elevated liver enzymes (aspartate/alanine transaminases) before treatment; these levels did not alter during therapy, nor did any deterioration occur in any of the other parameters.

All cases except Nos' V and VI were tested for adenosine deaminase (ADA) and purine necleoside phosphorylase (PNP) deficiency. Case No. III was found to have ADA deficiency while all the others were normal. 
The case reports of the children are summarised below and the tables show the immunologic findings.

Case I. D.M. Female. Diagnosis: severe combined immunodeficiency. Age 4 months at diagnosis (Table 1).

This child had, from the age of $5 \mathrm{wk}$, persistent upper respiratory tract infections, superficial skin infections of her face and scalp due to staphylococcus aureus and oral candidiasis resistant to local treatment. She had also required surgical drainage of a subcutaneous abscess, cultures of which had grown pseudomonas sp. She was failing to thrive and had intermittent diarrhoea. There were no palpable lymph nodes, no visible tonsillar tissue and no thymic shadow on chest $x$-ray. Investigations showed extremely low immunoglobulin levels, lymphopenia and eosinophilia with very low numbers of $T$ cells and undetectable $B$ cells in the blood. Candida skin test was negative.

She was treated with appropriate antibiotic therapy, oral nystatin and given immunoglobulins first as an intravenous infusion $(100 \mathrm{mg} / \mathrm{kg}$ ) and then as a weekly intramuscular dose of $25 \mathrm{mg} /$ $\mathrm{kg}$. TPI was started at the same time as these other measures.

Following therapy she underwent rapid clinical improvement with clearing of infection, cessation of the diarrhoea and good weight gain. At the same time her $T$ cell numbers increased to normal. After 3 months of therapy clinical improvement continued and, surprisingly, B cells appeared in normal numbers and immunoglobulins $\mathrm{A}$ and $\mathrm{M}$ increased suggesting endogenous immunoglobulin production. Candida skin test was still negative. At this stage we attempted to reduce the dosage of TPI to once weekly injections. This resulted in a recurrence of diarrhoea, slowing down of weight gain and a fall in $\mathbf{B}$ cell numbers and immunoglobulin levels. Increasing the dose again resulted in cessation of the diarrhoea, a rise in B cell numbers and immunoglobulins $\mathrm{A}$ and $\mathrm{M}$. However, she continues to gain weight poorly and has not produced isohaemagglutinins yet. Candida skin test remains negative. Therapy with TPI appears to have reconstituted partial immunity in this child.

Case II. K.M. Male. Diagnosis: severe combined immunodeficiency. Age at diagnosis, 8 months (Table 1).

For the first 6 months of life this child was well with no problems of diarrhoea or infection. He presented with a pneumonia resistant to initial antibiotic therapy; this was subsequently proven to be due to pneumocystis carinii and was successfully treated with high dose septrin and pentamidine. No lymph nodes were palpable, there was no visible tonsillar tissue and no thymic shadow was seen on chest $\mathrm{X}$-ray. Investigations showed a normal lymphocyte count but low $T$ cell and low normal $B$ cell numbers. Immunoglobulin levels were virtually absent in all classes.

He was started on immunoglobulins (1st dose as intravenous infusion then $25 \mathrm{mg} / \mathrm{kg} / \mathrm{wk}$ intramuscularly) and on TPI at $91 \frac{1}{2}$ months. For the next 15 months he remained relatively well with only minor upper respiratory infections and minor oral candidiasis responsive to treatment. He was kept on prophylactic septrin during this period. He gained weight and achieved normal developmental milestones but throughout had a persistent chronic cough. At 16 months of age his dose of TPI was reduced to once

Table 1. Immunologic parameters in relation to TPI therapy

\begin{tabular}{|c|c|c|c|c|c|c|c|c|}
\hline \multirow[b]{2}{*}{ Case } & \multirow[b]{2}{*}{ Test } & \multirow[b]{2}{*}{ Before } & \multicolumn{6}{|c|}{ After } \\
\hline & & & $2 \mathrm{wk}$ & 1 month & 2 months & 3 months & 6 months & $9-12$ months \\
\hline & L'cytes ${ }^{1}$ & 1680 & 2688 & 2015 & 2900 & 3360 & 1936 & 3150 \\
\hline & $\mathrm{ERFC}^{2}$ & $10 \%(9 \%)^{6}$ & N.D. ${ }^{7}$ & $60 \%$ & $67 \%$ & $49 \%$ & $56 \%$ & $66 \%$ \\
\hline \multirow[t]{7}{*}{ I } & $\begin{array}{l}\text { B cells } \\
\text { Igs }^{3}\end{array}$ & undetected & N.D. & undetected & $<1 \%$ & $12 \%$ & $1 \%$ & $5 \%$ \\
\hline & $G[30-110]^{4}$ & 6 & 69 & 47 & 59 & 80 & 40 & 21 \\
\hline & M [24-108] & $<4$ & $<4$ & 11 & 30 & 61 & 13 & 58 \\
\hline & A $[7-42]$ & $<2$ & $<2$ & 2 & 6 & 9 & 7 & 10 \\
\hline & PHA $^{5}$ & $3(6)$ & 405 & N.D. & 1.5 & 3 & 5 & 3.6 \\
\hline & L'cytes & 3840 & 1120 & & 2600 & 2726 & 1665 & 1425 \\
\hline & ERFC & $2 \%(5 \%)$ & $1 \%$ & & $4 \%$ & $2 \%$ & $3 \%$ & $1 \%$ \\
\hline \multirow[t]{7}{*}{ II } & $\begin{array}{l}\text { B cells } \\
\text { Igs }\end{array}$ & $6 \%$ & N.D. & & N.D. & N.D. & $7 \%$ & $20 \%$ \\
\hline & $\mathrm{G}[37-114]$ & $<4$ & N.D. & & N.D. & N.D. & 26 & 34 \\
\hline & $\mathrm{M}[41-180]$ & 11 & N.D. & & N.D. & N.D. & 7 & 11 \\
\hline & A [11-49] & $<2$ & N.D. & & N.D. & N.D. & 2 & 2 \\
\hline & PHA & $1.2(1)$ & N.D. & & 4.5 & 1 & 1 & 1 \\
\hline & L'cytes & 246 & & 108 & 693 & 348 & & \\
\hline & ERFC & $1 \%(4 \%)$ & & $1 \%$ & $7 \%$ & $22 \%$ & & \\
\hline \multirow[t]{6}{*}{ III } & $\begin{array}{l}\text { B cells } \\
\text { Igs }\end{array}$ & $5 \%$ & & $1 \%$ & N.D. & N.D. & & \\
\hline & G [26-98] & 48 & & 47 & 35 & 37 & & \\
\hline & $\mathrm{M}[18-84]$ & $<5$ & & $<5$ & 12 & 13 & & \\
\hline & A [4-28] & $<2$ & & 2 & 7 & 4 & & \\
\hline & PHA & 1 & & 1 & & 2.5 & & \\
\hline & & & & & $\frac{\text { Blo }}{\text { transf }}$ & & & \\
\hline
\end{tabular}

\footnotetext{
${ }^{1}$ Lymphocyte count per $\mathrm{mm}^{3}$ blood.

${ }^{2}$ Normal ranges for $\mathrm{T}$ and $\mathrm{B}$ cell numbers and PHA response are given in the methods section.

${ }^{3}$ Immunoglobulins in international units $/ \mathrm{ml}$. The normal ranges given are for the age of the children at presentation (12).

${ }^{4}$ Normal ranges of immunoglobulins.

${ }^{5}$ Expressed as stimulation index.

${ }^{6}$ Figures in parentheses represent the results after in vitro incubation of lymphocytes with TPI (when performed).

${ }^{7}$ N.D. $=$ not done.
} 
weekly with no clinical change. During the whole of this time no improvement in his immunologic tests occurred. At 20 months of age he developed a pseudomonas chest infection and his lung function deteriorated. In spite of extensive antibiotic therapy it was not possible to eradicate the organism. An attempt was made to reconstitute his immunity with a mismatched bone marrow graft from his father, using Cyclosporin A to try to prevent graft versus host disease. He died 10 days after the graft from a bleeding disorder of obscure etiology. Postmortem examination confirmed severe immunodeficiency with a rudimentary thymus and marked lymphoid depletion in the spleen and nodes. We conclude that TPI was not effective.

Case III. S.Y. Male. Diagnosis: severe combined immunodeficiency due to ADA deficiency. Age at diagnosis, 2 months (Table 1).

This baby presented with a chest infection, extensive oropharyngeal candidiasis (which had been resistant to topical treatments) diarrhoea and failure to thrive. There were no palpable lymph nodes and chest x-ray showed no thymic shadow. Investigations showed marked lymphopenia with very low numbers of $\mathrm{T}$ cells and low numbers of B cells. PHA response was absent as was delayed hypersensitivity response to candida antigen. Immunoglobulin levels showed absence of IgA and IgM but normal IgG, presumably of maternal origin. He needed treatment with systemic antifungal agents and antibiotics and was started on immunoglobulin injections $(25 \mathrm{mg} / \mathrm{kg} / \mathrm{wk})$. His general condition improved though he continued to have diarrhoea and failed to put on weight. At 9 wk of age he was started on TPI, which over the next month had no effect on either his weight gain and diarrhoea or on his immune function tests. At $12 \mathrm{wk}$ of age he was diagnosed as having ADA deficiency. He was therefore started on a course of weekly transfusions of fresh irradiated red cells $(20 \mathrm{ml} / \mathrm{kg}$ given as a partial exchange transusion), as a source of enzyme replacement, but was continued on TPI. Within 10 days of starting this treatment his general condition had markedly improved, he was gaining weight and his diarrhoea had stopped. PHA response had improved though was still subnormal. His lymphocyte count had increased but he still had low numbers of $\mathrm{T}$ cells. He is now $26 \mathrm{wk}$ old and still gaining weight. He has developed palpable lymph nodes and tests show partially reconstituted immunity. Currently he is on fortnightly red cell infusions, TPI, immunoglobulin injections and prophylactic antibiotics. The improvement obtained in this case could not have been due to TPI therapy alone since the major benefit occurred after red cell transfusions.

Case IV. Z. M. Female. Diagnosis: combined immunodeficiency. Age at diagnosis, 11 months (Table 2).

This child had been well until 7 months of age when she had developed intractable diarrhoea, failure to thrive and recurrent respiratory infections. She had required intensive dietary management, prophylactic antibiotics, immunoglobulin injections as well as parenteral nutrition for several months. Investigations revealed a low lymphocyte count with marked eosinophilia but a normal $\%$ of $\mathrm{T}$ cells. $\mathrm{B}$ cells and pre $\mathrm{B}$ cells were absent in blood and bone marrow. Immunoglobulins $A$ and $M$ were undetectable and $G$ was low (on immunoglobulin injections). PHA response was low and improved with in vitro use of TPI. Candida skin test was negative. At 18 months of age she was started on TPI (daily injections for 5 days followed by once weekly injections). Following this there was clinical improvement together with a marked increase in the PHA response. Candida skin test, however, remained negative. After 2 months the dose was reduced to once monthly, but a month later she had a relapse of her diarrhoea and so the dose was increased again. She then remained well while continuing on TPI though still lymphopenic and with a subnormal PHA response. At the age of 3 years 2 months an attempt was made to stop the TPI again with a further relapse, necessitating parenteral nutrition. She is now doing well on monthly injections of the extract, though her tests remain abnormal. TPI therapy appears to have restored partial immunity in this child.

Case V. R. T. Male. Diagnosis: T cell deficient. Age at diagnosis, 6 years (Table 2 ).
This boy, the sixth child in his family, had two siblings who died of infections in infancy. Apart from eczema in infancy he had been well until the age of 5 years, when he developed extensive herpetic infections on his face and groin which had slowly cleared without treatment. After this he failed to thrive, had persistent loose stools and at the age of 6 had an episode of septicaemia and pneumonia caused by haemophilus influenzae. Investigations showed eosinophilia with a normal lymphocyte count, slightly low $T$ cell numbers and an absent PHA response. Herpes antibody titres were low at 1 in 16 despite a further attack of herpes infection at this time. Since that time he has continued to have mild malabsorption and to require iron and folate supplements. $\mathrm{He}$ has recurrent chest infections requiring antibiotics. At age 10 years he developed a severe eruption of herpes simplex on legs, face, eyes and mouth, associated with a haemophilus chest infection. Again defective PHA response and low numbers of T cells were noted. He was treated with TPI together with topical idoxuridine to some of the lesions only and given antibiotics for his chest infection. Within 1 month of starting TPI, T cell numbers and PHA response had become normal but the virus isolation from the lesions persisted. Transient clearing of the lesions which received idoxuridine occurred but there was no change in the others. Later the lesions progressed and he required systemic antiherpes therapy (Acyclovir). He responded well and has been free from problems with herpes virus since then.

TPI was stopped after 3 months without any adverse effects. $\mathrm{He}$ has remained reasonably well though he is growing poorly and still getting frequent respiratory infections. His immune function tests though still subnormal are better than before treatment. TPI restored cell-mediated immunity but the viral infection persisted.

Case VI. V. B. Female. Diagnosis, Complete Di George Syndrome. Age at diagnosis, 7 wk (Table 2).

This child had been born at term with a birthweight of $4 \mathrm{lb}$ and had remained well until she had a convulsion and was hospitalized at $6 \mathrm{wk}$ of age. She was found to be hypocalcaemic and to have the signs of a large ventricular septal defect, subsequently confirmed by cardiac catheterisation. No thymic shadow was seen on chest $\mathrm{x}$-ray. Further investigation revealed low numbers of $\mathrm{T}$ cells which remained low after her calcium had been corrected. Treatment with TPI was started at $2 \frac{1}{2}$ months of age. There followed a transient mild improvement in \% (but not absolute numbers) of circulating $T$ cells. Her condition, however, soon deteriorated due to a proteus respiratory and urinary infection and deteriorating cardiac function. Despite pulmonary artery banding and vigorous antibiotic therapy she died at age 4 months. Postmortem confirmed the diagnosis of complete Di George Syndrome, with no evidence of thymus or parathyroid tissue found on serial sections of the neck and upper mediastinum. The child died before any possible benefits from TPI therapy could be assessed.

Case VII. M. A. Female. Diagnosis: T cell deficiency. Age at diagnosis, 22 months (Table 3).

This child presented with failure to thrive, diarrhoea and a history of frequent chest infections. She was found to have auto immune haemolytic anaemia, lymphopenia, eosinophilia, a subnormal PHA response and low T cell numbers. Intestinal biopsy showed partial villous atrophy with clusters of P.A.S. positive macrophages in the lamina propria. Yeast opsonization was also defective. B cells were not enumerated as immunoglobulin values were normal.

She was treated initially with fresh frozen plasma infusions, blood transfusions, tetracycline, metranidazole and steroids. This improved her diarrhoea and her haemolytic anaemia but as her immune function was still abnormal she was started on TPI at the age of 2 years 1 month. The TPI had no effect clinically or on her immune function tests and was stopped after 2 months. She is still failing to thrive with persistent diarrhoea. Her auto immune haemolytic anaemia is under moderate control on daily steroid therapy. No benefit was observed following TPI therapy.

Case VIII. M. H. Female. Diagnosis: T cell deficiency. Age at diagnosis, 11 months (Table 3).

This child had been well until 11 months of age, when she 
Table 2. Immunologic parameters in relation to TPI therapy

\begin{tabular}{|c|c|c|c|c|c|c|c|c|}
\hline \multirow[b]{2}{*}{ Case } & \multirow[b]{2}{*}{ Test } & \multirow[b]{2}{*}{ Before } & \multicolumn{6}{|c|}{ After } \\
\hline & & & $2 \mathrm{wk}$ & 1 month & 2 months & 3 months & 6 months & $9-12$ months \\
\hline \multirow{7}{*}{ IV } & L'cytes $^{1}$ & 609 & 696 & 492 & & & N.D. & 600 \\
\hline & $\mathrm{ERFC}^{2}$ & $86 \% \%^{6}$ & N.D. ${ }^{7}$ & N.D. & & & N.D. & $74 \%$ \\
\hline & $\begin{array}{l}\text { B cells } \\
\text { Igs }^{3}\end{array}$ & undetected & undetected & N.D. & & & N.D. & N.D. \\
\hline & $G[38-138]^{4}$ & 21 & & 64 & & & N.D. & N.D. \\
\hline & $M[52-240]$ & $<1$ & N.D. & $<1$ & & & N.D. & N.D. \\
\hline & $A[18-53]$ & $<1$ & & $<1$ & & & N.D. & N.D. \\
\hline & PHA $^{5}$ & 2 & 12 & 30 & & & 1.5 & 4 \\
\hline \multirow{7}{*}{ V } & L'cytes & 1875 & 2310 & 3744 & 2700 & & & 3978 \\
\hline & ERFC & $40(48 \%)$ & $65 \%$ & $53 \%$ & $63 \%$ & & & $49 \%$ \\
\hline & $\begin{array}{l}\text { B cells } \\
\text { Igs }\end{array}$ & $8 \%$ & N.D. & $\because$ N.D. & N.D. & & & $12 \%$ \\
\hline & G [46-200] & 94 & N.D. & N.D. & 81 & & & 101 \\
\hline & M [52-240] & 78 & N.D. & N.D. & 136 & & & 98 \\
\hline & A [48-180] & 73 & N.D. & N.D. & 66 & & & 48 \\
\hline & PHA & $1(1)$ & 10 & 20 & 30 & & & 3 \\
\hline \multirow{7}{*}{ VI } & L'cytes & 2400 & 896 & 812 & & & & \\
\hline & ERFC & $8 \%$ & $25 \%(38 \%)$ & $11 \%$ & & & & \\
\hline & $\begin{array}{l}\text { B cells } \\
\text { Igs }\end{array}$ & $13 \%$ & $20 \%$ & $8 \%$ & & & & \\
\hline & $\mathrm{G}[26-98]$ & 60 & N.D. & N.D. & & & & \\
\hline & $\mathrm{M}[18-84]$ & 94 & N.D. & N.D. & & & & \\
\hline & $\mathrm{A}[4-28]$ & $<2$ & N.D. & N.D. & & & & \\
\hline & PHA & N.D. & 20 & N.D. & & & & \\
\hline
\end{tabular}

\footnotetext{
${ }^{1}$ Lymphocyte count per $\mathrm{mm}^{3}$ blood.

${ }^{2}$ Normal ranges for $\mathrm{T}$ and $\mathrm{B}$ cell numbers and PHA response are given in the methods section.

${ }^{3}$ Immunoglobulins in international units $/ \mathrm{ml}$. The normal ranges given are for the age of the children at presentation (12).

${ }^{4}$ Normal ranges of immunoglobulins.

${ }^{5}$ Expressed as stimulation index.

${ }^{6}$ Figures in parentheses represent the results after in vitro incubation of lymphocytes with TPI (when performed).

${ }^{7}$ N.D. $=$ not done.
}

developed a severe pneumonia. Although she did not have the rash typical of measles she showed seroconversion to this virus by complement fixation testing. A sibling had died of infection in infancy and a diagnosis of Nezelof's syndrome had been made at postmortem examination.

Investigations showed a low lymphocyte count, low numbers of $\mathrm{T}$ cells and a very poor PHA response. In vitro tests with TPI showed an increased PHA response but no effect on the E rosetting (T) cell numbers. She had a high IgM, normal IgG and low IgA. Subsequently it has been shown that she could only produce antibody activity in the IgM class and no serum anti tetanus activity (IgG) could be detected after 3 immunizations. Her immune function improved as she recovered from the pneumonia but never returned to normal. At 14 months she was given a trial of TPI for a 3 month period. This had no consistent effect on her immune function tests but during this period she remained clinically well and actually put on weight. At 17 months TPI was stopped. At the same time she was started on immunoglobulins as she had been shown to be incapable of producing functional IgG antibodies. She remained stable, though failing to thrive and with intermittent diarrhoea for some months. At the age of $2 \frac{1}{2}$ years she suddenly deteriorated over a few wk and died. At postmortem she was found to have multiple small bowel ulcers and perforations. No infectious agent was identified. Histology of the lymph nodes showed lymphoid depletion confirming the diagnosis. We conclude that therapy with TPI was not effective in this child.

\section{DISCUSSION}

The syndromes of $\mathbf{T}$ cell deficiency and severe combined immunodeficiency although exceedingly rare are clearly heterogeneous. In only two instances have single gene enzyme defects (adenosine deaminase and purine nucleoside phosphorylase deficiency) been determined (14) but in some other instances it is possible to define where in $T$ cell differentiation the defect lies (8). In the differentiation and maturation of fully immunocompetent $T$ cells it is thought that cell-cell contact is necessary for the early stages with humoral factors important later. Hence, on theoretical grounds, it could be postulated that thymic humoral factors may improve $\mathrm{T}$ cell numbers and function in children with isolated $\mathrm{T}$ cell deficiency if the block is late in differentiation, whereas no such benefit might be obtained in severe combined immunodeficiency where the block is probably earlier. The initial reports of therapeutic efficacy of crude calf thymic extracts were indeed in $T$ cell deficiency and the authors stressed that the children's in vivo response paralleled that of in vitro improvement in $\mathrm{T}$ cell numbers as determined by $\mathrm{E}$ rosette formation $(1,19)$.

Our experience in the use of TPI for the treatment of eight children with $\mathrm{T}$ cell or combined immunodeficiency does not correspond with that reported previously. The two children in whom we could show most benefit (Cases I and IV) both had combined immunodeficiency. In neither child could we demonstrate an in vitro improvement in immune function with TPI prior 
Table 3. Immunologic parameters in relation to TPI therapy

\begin{tabular}{|c|c|c|c|c|c|c|c|c|}
\hline \multirow[b]{2}{*}{ Case } & \multirow[b]{2}{*}{ Test } & \multirow[b]{2}{*}{ Before } & \multicolumn{6}{|c|}{ After } \\
\hline & & & $2 \mathrm{wk}$ & 1 month & 2 months & 3 months & 6 months & $9-12$ months \\
\hline \multirow{7}{*}{ VII } & L'cytes $^{1}$ & 698 & 660 & N.D. & 946 & & 1221 & 1000 \\
\hline & $\mathrm{ERFC}^{2}$ & $22 \%^{6}$ & $35 \%$ & N.D. & N.D. & & N.D. & $45 \%$ \\
\hline & $\begin{array}{l}\text { B cells } \\
\text { Igs }^{3}\end{array}$ & N.D. ${ }^{7}$ & N.D. & N.D. & N.D. & & N.D. & N.D. \\
\hline & $\mathrm{G}[38-175]^{4}$ & 216 & & & 163 & & & \\
\hline & M [52-240] & 165 & N.D. & N.D. & 206 & & N.D. & N.D. \\
\hline & A [21-92] & 157 & & & 116 & & & \\
\hline & $\mathrm{PHA}^{5}$ & 2.5 & 3 & 6 & N.D. & & 2.5 & 2.5 \\
\hline \multirow{7}{*}{$\mathrm{VIII}^{8}$} & L'cytes & $246-1073$ & 1400 & 517 & & 351 & 817 & 260 \\
\hline & ERFC & $5 \%-54 \%(17 \%)^{9}$ & $30 \%$ & $7 \%$ & & $6 \%$ & N.D. & $18 \%$ \\
\hline & $\begin{array}{l}\text { B cells } \\
\text { Igs }\end{array}$ & N.D. & N.D. & N.D. & N.D. & N.D. & N.D. & N.D. \\
\hline & G [38-138] & 97 & 98 & 65 & & 52 & & 141 \\
\hline & $M[52-240]$ & 310 & 98 & 27 & & 76 & N.D. & 141 \\
\hline & A [18-53] & 9 & 41 & 14 & & 33 & N.D. & 36 \\
\hline & PHA & $\begin{array}{c}1-7 \\
(1-7)\end{array}$ & 3 & 5 & & 1.5 & 1.2 & 1.1 \\
\hline
\end{tabular}

\footnotetext{
${ }^{1}$ Lymphocyte count per $\mathrm{mm}^{3}$ blood.

${ }^{2}$ Normal ranges for $T$ and $B$ cell numbers and PHA response are given in the methods section.

${ }^{3}$ Immunoglobulins in international units/ml. The normal ranges given are for the age of the children at presentation (12).

${ }^{4}$ Normal ranges of immunoglobulins.

${ }^{5}$ Expressed as stimulation index.

${ }^{6}$ Figures in parentheses represent the results after in vitro incubation of lymphocytes with TPI (when performed).

${ }^{7}$ N.D. = not done.

${ }^{8}$ There was considerable fluctuation in many of the parameters tested in this patient before therapy with TPI. The ranges of values obtained are therefore quoted. Such fluctuation was not found in any of the other patients.

${ }^{9}$ ERFC value done, in parallel, without TPI was $20 \%$.
}

to starting treatment. It is possible that the concentration used for in vitro testing was suboptimal in our hands as it is known that the increase in $\mathrm{E}$ rosette formation is dose dependent $(3,6)$. However, using the same conditions of incubation, we have observed an increase in numbers of $\mathrm{E}$ rosette forming cells in many children with Histiocytosis X (unpublished observations).

Case I, the child with severe combined immunodeficiency, has shown reconstitution of $T$ cell numbers and function as well as clinical improvement while on TPI injections. Surprisingly, she also showed a dramatic appearance of B cells plus immunoglobulin production while on therapy suggesting that differentiation of $B$ cells from precursors is under $T$ cell control. When the injections were reduced to once weekly her clinical condition deteriorated with poor weight gain, but since increasing to twice weekly, this has improved. In two other children with severe combined immunodeficiency (Cases II and III, the adenosine deaminase deficient child) we could demonstrate no in vitro or in vivo improvement in immunologic function. This emphasizes the heterogeneity of the syndrome and suggests that one variety at least is due to deficiency of thymic humoral factors. However, due to the lack of initial in vitro response to TPI, it is not possible to distinguish this variety at present other than by therapeutic trial.

The improvement observed in Case III was, undoubtedly, due to the red cell transfusions given. However, TPI therapy was continued because of previous reports suggesting that thymic hormone may improve the response to red cell transfusions in ADA deficiency (15).

We are unsure of the correct dose of TPI necessary to maintain good health. In the two children with combined immunodefiency, Case I began to deteriorate when the dose was reduced to $1 \mathrm{mg}$ / $\mathrm{kg}$ weekly with subsequent recovery upon reinstituting twice weekly injections. Case IV showed good in vitro and in vivo responses to the initial weekly doses and although she continued thriving when the dose was reduced to once monthly, her in vitro tests declined to subnormal. There is no doubt that the extract is necessary for her survival since she became dangerously ill and required intravenous feeding when it was stopped for a 3 month period.

Our results in $\mathrm{T}$ cell deficiency are disappointing. Previous reports have indicated reconstitution of cell-mediated immunity in such children (1) and successful recovery from haemorrhagic chickenpox in immunosuppressed patients after therapy with TPI (3). In the one child with $T$ cell deficiency in whom we could demonstrate reconstitution of cellular immunity (Case V), the extract apparently had little effect on the course of the herpes simplex viral illness which only resolved upon treatment with a specific antiviral agent. In the other children with $T$ cell deficiency, we could show no clinical benefit or improvement in tests of cellular immune function, though in Case VI we may have been getting a response before she died from her other problems. We found no adverse effects of treatment with TPI and this corresponds with published reports. There was no alteration in haematologic profile or in renal and liver function. However, because the product is derived from calf thymus, it should be used with caution in patients with allergy to bovine proteins. Indeed, hypersensitivity has been noted previously when thymic extracts have been used to treat severely atopic individuals (13). Two of our cases, Case V (with a history of eczema in infancy) and Case VII (with autoimmune haemolytic anaemia) might have been expected to have a tendency towards allergic reactions. However, we observed no allergic reactions at any time in any of the children.

There may be advantages to using a well characterized synthetic peptide over a crude extract which is difficult to standardise and may contain foreign antigenic material. However, it seems probable there is a family of thymic hormones affecting different stages of $T$ cell differentiation. Hence it is possible that the crude extract 
will be of greater benefit to a wider range of $\mathrm{T}$ cell deficient patients. A rational approach to this problem might be to use the synthetic peptide hormone (TP5) first and if the response is poor, to change over to the crude calf thymic extract (TPI).

We believe that a therapeutic trial of thymic hormones is indicated for all children with defects of cell-mediated immunity when no other specific treatments are available.

\section{REFERENCES AND NOTES}

1. Aiuti, F., Ammirati, P., Fiorilli, M., D'Amelio, R., Franchi, F., Calvani, M., and Buscino, L.: Immunological and clinical investigations on a bovine thymic extract, therapeutic applications in primary immunodeficiencies. Pediatr. Res., 13: 797 (1979)

2. Bach, J. R., Dardenne, M., and Pleau, J. M.: Biochemical characterisation of a serum thymic factor. Nature, 266: 55 (1977).

3. Buscino, L., Rossi, P., Quinti, I., and Perlini, R.: Therapy with TP-1 of viral diseases in immunodeficient patients. In: F. Aiuti and H. Wigzell, Ed: Proceedings of the Serono Symposia Vol. 38 p. 295 (Academic Press London 1980).

4. Falchetti, R., Bergesi, G., Eshkol, A., Cafiero, C., Adorini, L., and Caprino, L.: Pharmacological and biological properties of a calf thymus extract (TP-1). Drugs Expt. Clin. Res. 3(2): 39 (1977).

5. Falchetti, R., Cafiero, C., and Caprino, L.: Bioassay for thymic extracts; guinea pig spleen lymphocytes-rabbit red blood cells rosette method. Cancer Biochem. Biophys., 4(2): 69 (1979).

6. Falchetti, R. and Caprino, L.: Immunological aspects of TP-1 activity. In: F. Aiuti and H. Wigzell, Ed: Proceedings of the Serono Symposia Vol. 38 p. 219 (Academic Press London 1980).

7. Fiorilli, M., Aiuti, F., Ammirati, P., Pandolfi, F., and Sirianni, M. C.: Immunological and clinical investigation of a bovine thymic extract. I. In vitro effect on T-cell differentiation in normal and pathological conditions. Annali Sclavo., 21: 370 (1979).

8. Gelfand, E. W., Dosch, H-M., Shore, A., Limatibul, S., and Lee, W. W.: Role of the thymus in human $T$ cell differentiation. In: E. W. Gelfand and H-M. Dosch, Ed: Biological basis of Immunodeficiency, p. 39 (Raven Press, New York, 1980).

9. Goldstein, A. L., Slater, F. D., and White, A.: Preparation, assay and partial purification of a thymic lymphocytopoetic factor (thymosin). Proc. Nat. Acad. Sci., 56: 1010 (1966).
10. Goldstein, G., Scheid, P., Boyse, E. A., Schlesinger, D. H., and Van Wauwe, J.: A synthetic pentapeptide with biological activity characteristic of the thymic hormone thymopoeitin. Science, 204: 1309 (1979).

11. Hayward, A. R.: Immunodeficiency. In: Current topics in Immunology Series 6: 77 (Arnold 1977)

12. Hobbs, J. R.: Personal communication to Turner, M. W. In: Holborow, E. J. and Reeves, W. G. Ed: Immunology in Medicine, p. 125. (Academic Press, London. Grune and Stratton, New York. 1977).

13. Hobbs, J. R., Byrom, N. A., Campbell, M.A., Copeman, P. W. M., Gibbs, M., Lane, A. M., Perez, A., Staughton, R. C. D., and Timlin, D. M.: Thymosin inducible lymphocytes in atopy. In: F. Aiuti and H. Wigzell, Ed: Proceedings of the Serono Symposia Vol. 38 p. 143 (Acadernic Press New York, New York 1980).

14. Meuwissen, H. J., Parker, K., and Cook, B.: Inborn errors of specific immunity: adenosine deaminase deficiency and purine nucleoside phosphorylase deficiency. In: F. Füttler, J. W. T. Seakins, and R. A. Harkness, Ed: Inborn errors of Immunity and Phagocytosis. p. 89 (MTP Press, 1979).

15. Rubinstein, A., Hirschhorn, R., Sicklick, M., and Murphy, R. A.: In vivo and in vitro effects of thymosin and adenosine deaminase on adenosine-deaminasedeficient lymphocytes. N. Engl. J. med., 300: 387 (1979).

16. Schlesinger, D. H. and Goldstein, G,: The amino acid sequence of thymopoetin II. Cell 5(4): 361 (1975).

17. Thurman, G. B., Marshall, G. D., Low, T. L. K., and Goldstein, A. L.: Thymosin: Structural studies and immuno-regulatory role in host immunity. In: F. Aiuti and H. Wigzell, Ed: Proceedings of the Serono Symposia. Vol. 38 p. 175 (Academic Press London 1980).

18. Trompeter, R. S., Layward, L., and Hayward, A. R.: Primary and secondary abnormalities of $T$ cell subpopulations. Clin. Exp. Immunol., 34: 388 (1978).

19. Wara, D. W., Goldstein, A. L., Doyle, N. E., and Ammann, A. J.: Thymosin activity in patients with cellular immunodeficiency. N. Engl. J. Med., 292: 70 (1975).

20. Dr. Davies holds a research training fellowship from Action Research-The National Fund for Research into Crippling Diseases.

21. The authors would like to thank Mrs. M. Butler and Mrs. L. Layward for expert technical assistance, Dr. O. B. Eden for permission to report case VI and Serono Laboratories for supplying TPI.

22. Requests for reprints should be addressed to: Dr. R. J. Levinsky, Department of Immunology, Institute of Child Health, 30 Guilford St., London WCIN IEH, England.

23. Received for publication June 2, 1981.

24. Accepted for publication November 17, 1981. 